\begin{tabular}{|c|c|c|}
\hline $\begin{array}{l}\text { PKS } \\
\text { PUBLIC } \\
\text { KNDOLEDGE } \\
\text { PROJECT }\end{array}$ & $\begin{array}{c}\text { REVISTA DE GEOGRAFIA } \\
\text { (RECIFE) } \\
\text { http://www.revista.ufpe.br/revistageografia }\end{array}$ & $\begin{array}{l}\text { OJS } \\
\text { OPEN } \\
\text { JOLYNAL } \\
\text { SYSTEMS }\end{array}$ \\
\hline
\end{tabular}

\title{
CONDICIONANTES GEOMORFOLÓGICAS E HIDROCLIMÁTICAS PARA HIPERSALINIZAÇÃO EM SISTEMAS LACUSTRES COSTEIROS DO SEMIÁRIDO BRASILEIRO
}

\author{
David Hélio Miranda de Medeiros ${ }^{1}$, Lidriana de Souza Pinheiro ${ }^{2}$; João Paulo de \\ Oliveira Medeiros ${ }^{3}$; Renato de Medeiros Rocha ${ }^{4}$
}

\footnotetext{
${ }^{1}$ Doutorando em Ciências Marinhas Tropicais - PPGCMT, Universidade Federal do Ceará - UFC. Email: davidgeo.ambiental@yahoo.com.br

${ }^{2}$ Professora Associada I do Instituto de Ciências do Mar, Universidade Federal do Ceará - UFC. Email: lidriana@ufc.br

${ }^{3}$ Graduando em Engenharia de Pesca, Universidade Federal Rural do Semiárido - UFERSA. Email: j.paulo08@hotmail.com

${ }^{4}$ Professor Associado III do Departamento de Geografia DGC-CERES, Universidade Federal do Rio Grande do Norte - UFRN. Email: renatocaico@yahoo.com.br
}

Artigo recebido em 08/12/2017 e aceito em 09/03/2018

\begin{abstract}
RESUMO
Esta pesquisa analisa a associação de fatores geomorfológicos, hidroclimáticos e drenagens, para a constituição de um sistema lacustre suscetível aos processos de hipersalinização e deposição evaporítica. Foi realizado um levantamento histórico de aspectos socioambientais integrados; utilizou-se imagens orbitais e de radar (SRTM), sendo extraídas as curvas altimétricas da área, e foram obtidos dados vetoriais da rede de drenagem; coletou-se dados secundários da característica salina das águas subterrâneas. A área de estudo provavelmente experimentou condições evolutivas ao longo do Holoceno, desde um sistema fluvial para estuarino-lagunar, até se tornar um sistema lacustre. Durante os períodos de estiagem de chuvas apresentava indícios de hipersalinização e ocorrência de deposição evaporítica natural. Portanto, salinização dessa área decorre de condições de restrição de drenagem, lençol freático e a elevada evapotranspiração, que promove ascensão capilar dos sais para superfície.

Palavras-chave: semiárido; sistema lacustre; hipersalinidade.
\end{abstract}

\section{GEOMORPHOLOGICAL AND HYDROCLIMACTIC FACTORS PROMOTE HYPERSALINIZATION IN COASTAL LACUSTRINE SYSTEMS IN THE BRAZILIAN SEMIARID REGION}

\begin{abstract}
This research examines the association between geomorphological and hydroclimatic factors and drainages, in the formation of susceptible lacustrine systems to hypersalinization processes and evaporitic deposition. An historical survey regarding the integrated socio-environmental aspects was made; orbital and radar (SRTM) images were used to extract the area's altimetry curves and the drainage network vector data was obtained. Then, secondary data was collected about groundwater's chemical properties. The study area probably evolved from a freshwater system to an estuarine-lagoon during Holocene, until it became a lacustrine system. Throughout the drought periods, the studied area experienced evidences of hypersalinization and natural evaporitic deposition occurred. Therefore, this area's salinization occurs due to drainage and groundwater table restriction conditions and evapotranspiration, which promote salt's capillary ascension to the surface.

Keywords: semiarid; lacustrine systems; hypersalinity.
\end{abstract}




\section{INTRODUÇÃO}

A hipersalinização nos interstícios dos sedimentos e em corpos hídricos é caracterizada pelas concentrações de sais superiores a 40 \% (MIRANDA et al., 2012; MEDEIROS et al., 2018). Bayly (1967) e Schoff (1967) associam a salinização como resultada da dissolução contínua de sais primitivos, que foram deixados pelo último evento de regressão marinha. Cruz e Melo (1968) e mais recentemente Ribeiro et al. (2016) justificam que as altas salinidades decorrem do efeito de capilaridade dos solos, sobretudo em regiões áridas e semiáridas. Oliveira e Batista (1998) ressaltaram a associação de aspectos climáticos (aridez), ambiente edáfico e litológico para salinização.

As condições climáticas semiáridas apresentam taxas de evaporação e evapotranspiração maiores do que as precipitações, determinando baixos influxos de águas aos litorais, podendo ocasionar hipersalinização sazonal e/ou permanente das águas estuarinas e de outros ambientes costeiros associados (RAMOS SILVA, 2004; MORAIS; PINHEIRO, 2011; VALLE-LEVINSON; SCHETTINI, 2016; MEDEIROS, 2016). Dentre um dos ambientes vulneráveis à hipersalinização, estão os sistemas lacustres costeiros, que regionalmente são formados pela associação de processos, como o avanço de dunas, variações da linha da costa, padrões de drenagem ou mesmo por influência antrópica (PINHEIRO; MORAIS, 2010).

Alguns desses sistemas lacustres mantêm ligação direta com o mar através de pequenos cursos d'água que podem sazonalmente serem barrados, ou por percolação. Condições propícias para à alta salinidade (sazonal) em sistemas lacustres e/ou estuarinoslagunares, associadas ao regime da aridez e semiaridez, foram relatadas em diversas regiões do mundo, como na Laguna Guerrero Negro e Laguna Ojo de Liebre (POSTMA, 1965), Baía Shark (SMITH e ATKINSON, 1983; BURLING, IVEY e PATTIARATCHI, 1999; NAHAS, PATTIARATCHI e IVEY, 2005), Laguna Madre of Texas (SMITH, 1988), Lagoa Puttalam (ARULANANATHAN et al., 1995), Laguna San Ignacio (WINANT; GUTIERREZ DE VELASCO, 2003; GUTIERREZ DE VELASCO; WINANT, 2004). No Brasil, esses aspectos foram observados na Lagoa de Araruama (KJERVE et al., 1996), no sistema estuarinolagunar do Rio Mal Cozinhado (PINHEIRO, 2003) e Lagoa do Catú (PINHEIRO; MORAIS, 2010), dentre outros.

Nesse contexto, no litoral setentrional do Estado do Rio Grande do Norte observouse que até o início da presente década (2010-2020) existia um sistema lacustre no município de Areia Branca (RN), que durante os períodos de estiagem apresentava indícios de hipersalinização, com a deposição evaporítica natural (Figura 1). 
Cabe destacar, que a partir do ano de 2014, essa área passou a ter fluxo de água marinha perene, uma vez que foi incorporada por uma atividade salineira. Portanto, a presente pesquisa objetiva analisar a associação de fatores geomorfológicos, hidroclimáticos e drenagens, na constituição de um sistema lacustre suscetível aos processos de hipersalinização e deposição evaporítica.

Figura 1 - Localização da área de estudo.

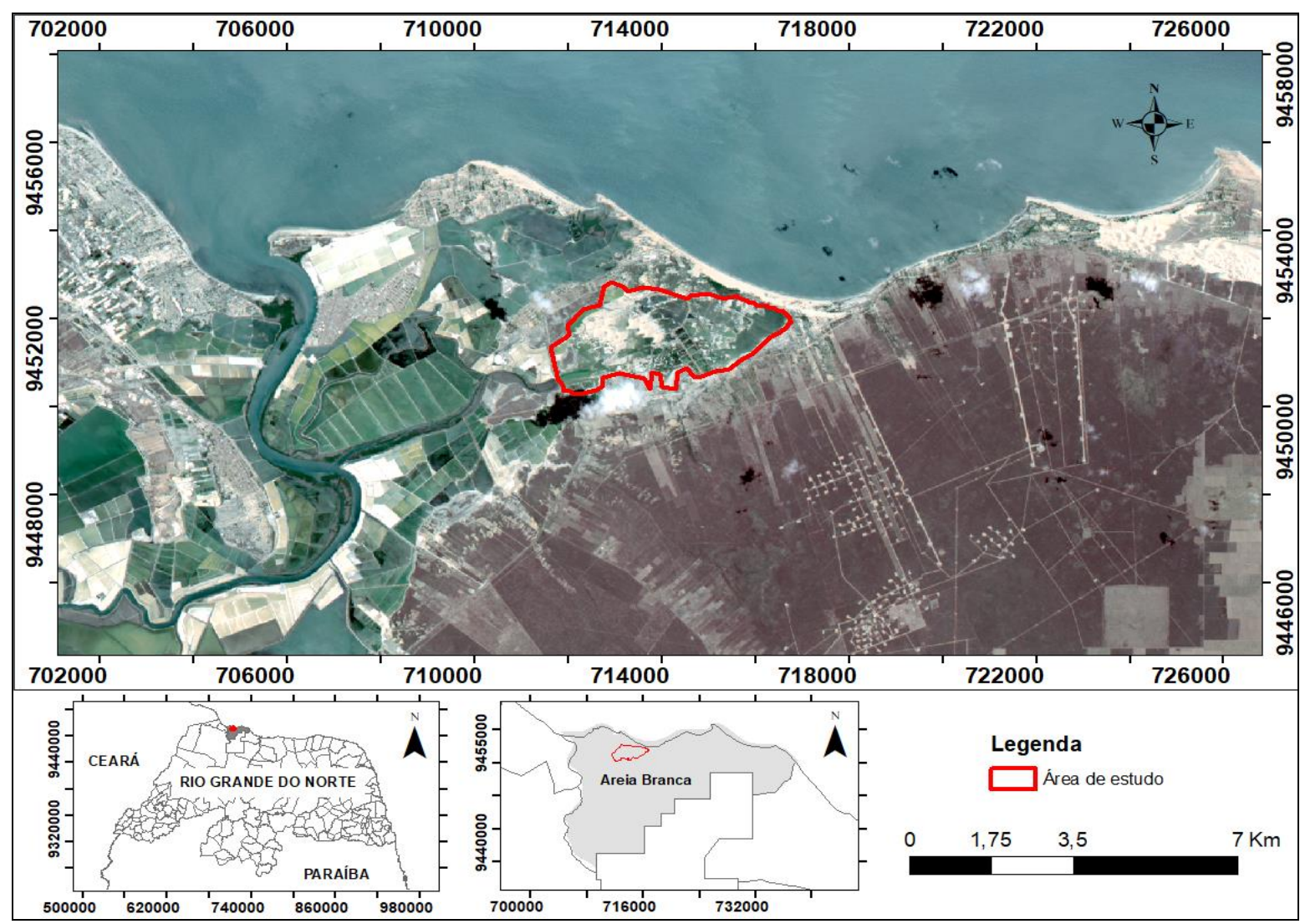

Fonte: Os autores (2018).

\section{MATERIAL E MÉTODOS}

Inicialmente foram realizadas revisões bibliográficas sobre os aspectos históricos dessa área, através de consulta em acervo de bibliotecas municipais, museus locais e acervo literário de instituições regionais de ensino superior. Foram adquiridas imagens de acesso gratuito, através do site do Instituto Nacional de Pesquisas Espaciais (INPE), United States Geological Survey (USGS) e Google Earth, optando pelo critério de seleção baseado nas cenas com boa qualidade e não comprometidas por cobertura de nuvens na área desejada, entre os anos de 2004 e 2009. 
As imagens foram georreferenciadas na grade de coordenadas UTM (Universal Transversa de Mercator). Todas as imagens foram submetidas a um processo de reprojeção, sendo adicionado e transformado a sua posição (geometria) para um sistema de coordenadas mais adequado, sendo adotado o Datum de referência para o SIRGAS2000 Zona 24 Sul. Em seguida, foi realizado processo de recorte para o enquadramento da área de estudo.

Com relação aos lençois freáticos dessa área, foram consultadas informações através do levantamento das águas subterrâneas do município de Areia Branca (RN), realizada no ano de 2005 pelo Ministério das Minas e Energia, que efetuou o cadastramento das fontes de abastecimento por água subterrânea (poço tubular, poço escavado e fonte natural), definindo medidas de condutividade elétrica, dentre outras análises físico-químicas, que atestaram a tendência salina das águas nessa localidade (MASCARENHAS et al., 2005).

Também foram realizados trabalhos de mapeamentos através do uso de imagens Shuttle Radar Topography Mission (SRTM), que possuem informações altimétricas com resolução espacial de 30 metros. Foram obtidas shapefiles de drenagem regional, disponibilizados gratuitamente nos sites da Agência Nacional de Águas, do Instituto Brasileiro de Geografia e Estatística e Companhia de Pesquisas de Recursos Minerais.

\section{RESULTADOS E DISCUSSÕES}

Os primeiros relatos históricos sobre essa área e entorno, foram registrados em meados do séc. XVII, quando da ocupação holandesa no litoral do Nordeste brasileiro, atestando a existência de extensas áreas com depósitos evaporíticos superficiais (ROSADO; ROSADO, 1987). Rosado; Rosado op. cit. também apresentam relatos de antigos pescadores do município de Areia Branca (RN), que afirmaram ao caso do "aterramento" do canal estuarino do Rio Morro Branco, realizado pelos holandeses. Essas informações demonstram alterações ambientais ocorridas desde o séc. XVII, e mais recente (séc. XX), como pela construção de uma rodovia e atividade de carcinicultura.

Nesse sentido, essas interferências antrópicas, associadas à propensão natural para formação de dunas na costa setentrional do Nordeste do Brasil, provavelmente provocaram a interrupção do fluxo de águas provenientes do Rio Morro Branco e com o oceano adjacente, condicionando na evolução de um sistema fluvial para um sistema lacustre, e formação de praias adjacentes.

As condições evolutivas ao longo do Quaternário foram confirmadas por Maia (2012), que estudando a geocronologia do vale do Rio Apodi-Mossoró, por meio de datações 
LOE/SAR, afirmou que a área de estudo, apresenta depósitos Holocênicos, caracterizados por aluviões e sedimentos costeiros. As variações do nível do mar também condicionaram à evolução geomorfológica local, visto que os depósitos fluviomarinhos foram associados com data invariavelmente da eustasia positiva Holocênica, que teve seu ápice há 5.000 A.P. (BEZERRA et al., 2003).

Essa é uma característica marcante de litorais situados em regiões semiáridas, visto que a velocidade dos ventos é mais intensa, juntamente com o transporte e disponibilidade de sedimentos, fazendo com que o domínio das formações arenosas, sob a forma de dunas, contribua significativamente para a obstrução das reentrâncias costeiras (MORAIS et al., 2002). Em consequência, as drenagens de pequeno porte evoluem para sistemas fluviolagunares ou estuarino- lagunares (KJERFVE, 1994; MARTIN; DOMINGUEZ, 1994; PINHEIRO; MORAIS, 2010), apresentando em alguns casos, condições de hipersalinização, ou seja, salinidade superiores a 50 (KJERFVE et al., 1996), como pela deposição evaporítica na área de estudo (Figura 2).

Figura 2 - Disposição hipersalina na área de estudo, em 27 de julho de 2005.

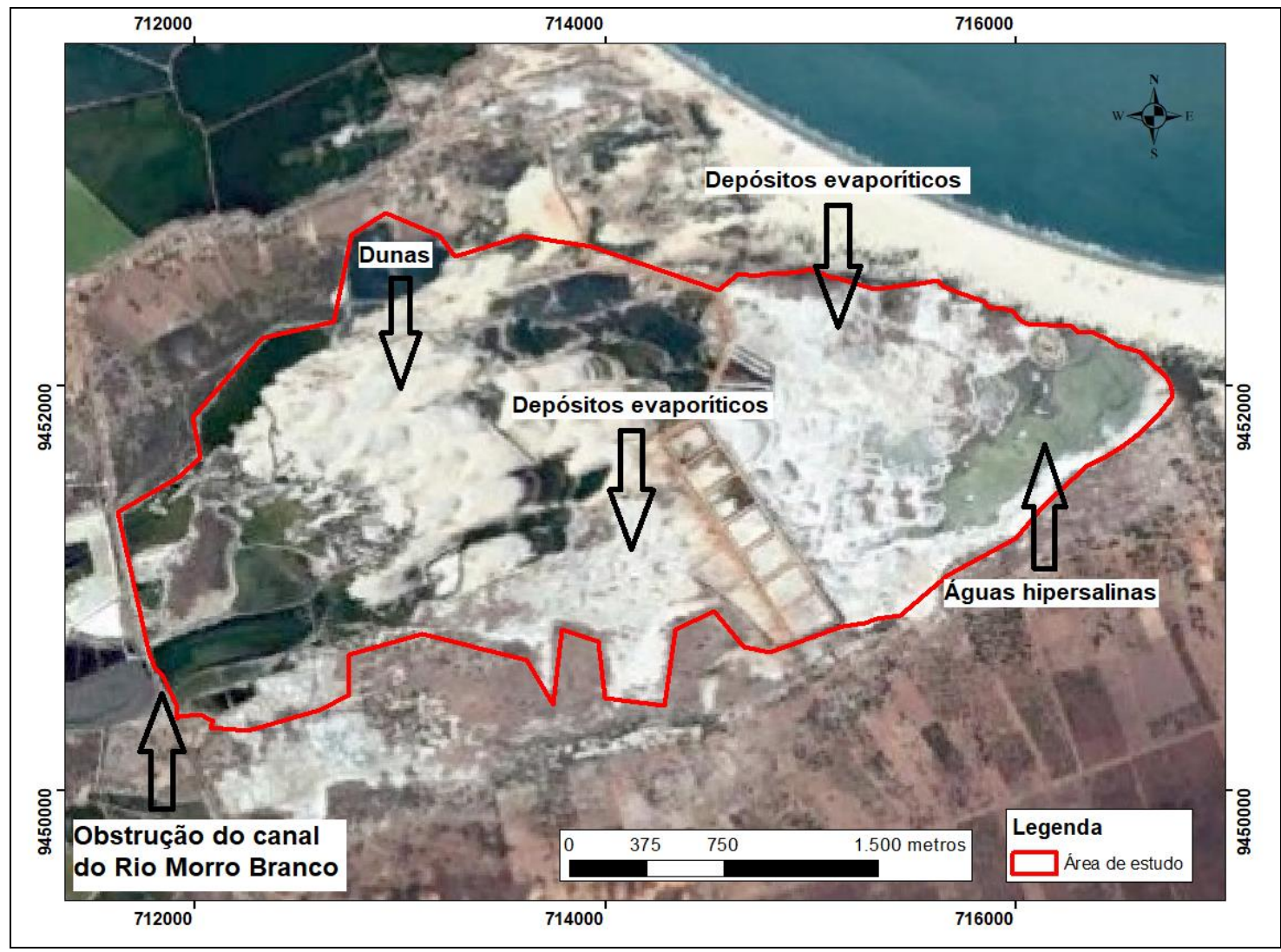

Fonte: Os autores (2018). 
Esse sistema de tendência hipersalina, provavelmente apresentava águas de origem diversa e de composição química diferenciada. Inicialmente deveria apresentar proporção iônica parecida a das salmouras de origem marinha, uma vez que em épocas pretéritas teve contato com o mar (ROSADO; ROSADO, 1987). As águas marinhas que ficaram aprisionadas evaporam em sua totalidade, após o fechamento natural (através da migração de dunas) ou artificial (realizado pelos holandeses) do contato superficial com as águas marinhas. No entanto, esses sais primários novamente foram dissolvidos nas águas das chuvas, descargas da drenagem fluvial e potencial aquífero das dunas, assim como influência do lençol freático salino (BAYLY, 1967), desfigurando em certo modo a sua composição primitiva devido aos novos aportes de água ou, pelo contrário, podem caracterizar-se por apresentar composições iônicas absolutamente distintas das que definem as salmouras de origem marinha.

A natureza salina dessa área é corroborada a partir do levantamento da qualidade das águas subsuperficiais, realizado no ano de 2005 pela CPRM (Figura 3). Os resultados das análises mostraram valores oscilando de 442 e $8.775 \mathrm{mg} / \mathrm{L}$ de sólidos totais dissolvidos. De acordo com a classificação adotada por Mascarenhas et al., (2005), as águas subterrâneas nessa localidade são de predominância salobras e salinas (Figura 4).

Figura 3 - Distribuição espacial da concentração de sólidos dissolvidos totais (mg/L) em poços subterrâneos no entorno da da área de estudo.

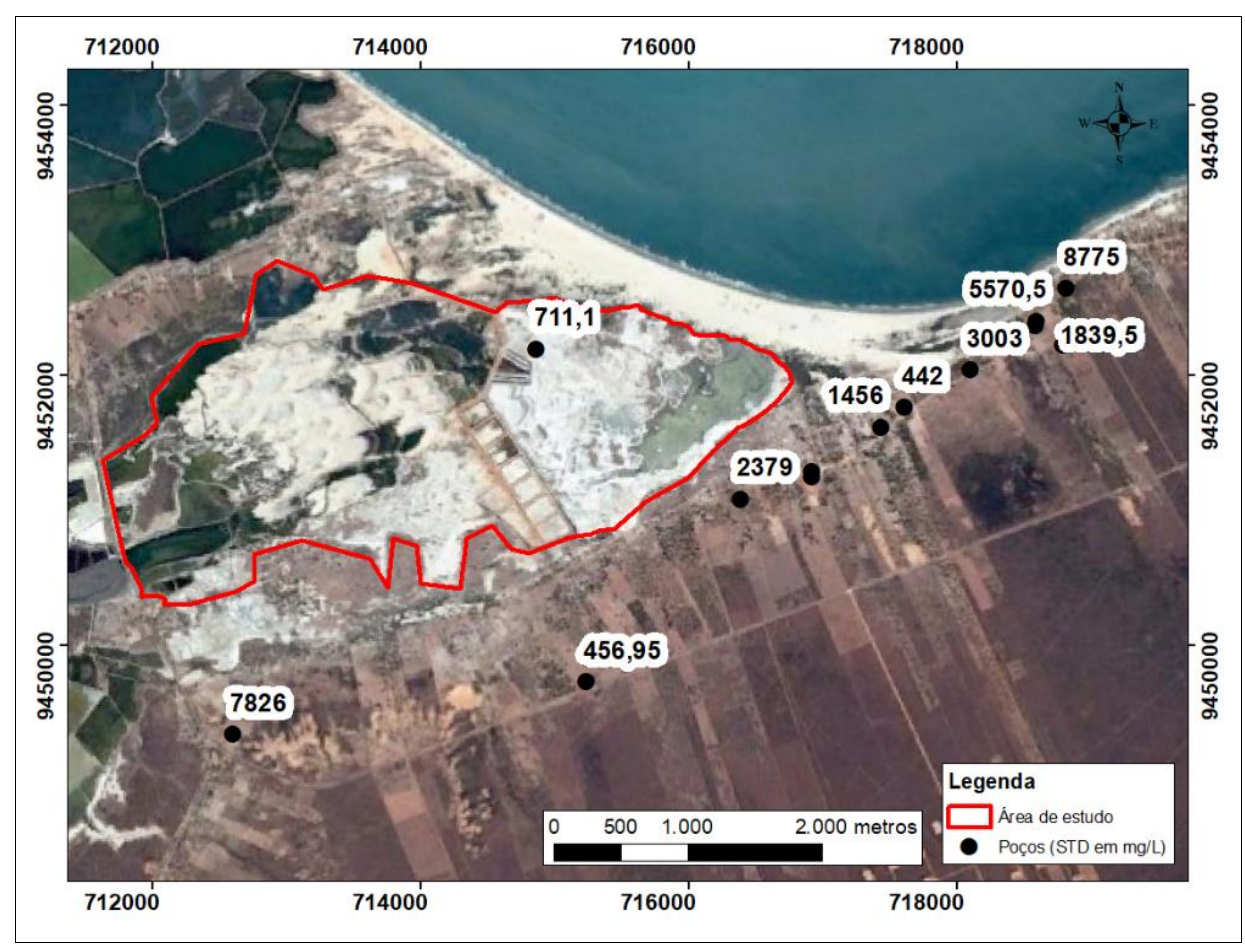

Fonte: Dados de STD dos poços extraídos da base de dados de Mascarenhas et al., (2005). Medeiros et al, 2018 ISSN 0104-5490 
Figura 4 - Classificação da concentração de sólidos dissolvidos totais (mg/L) em poços subterrâneos no entorno da da área de estudo.

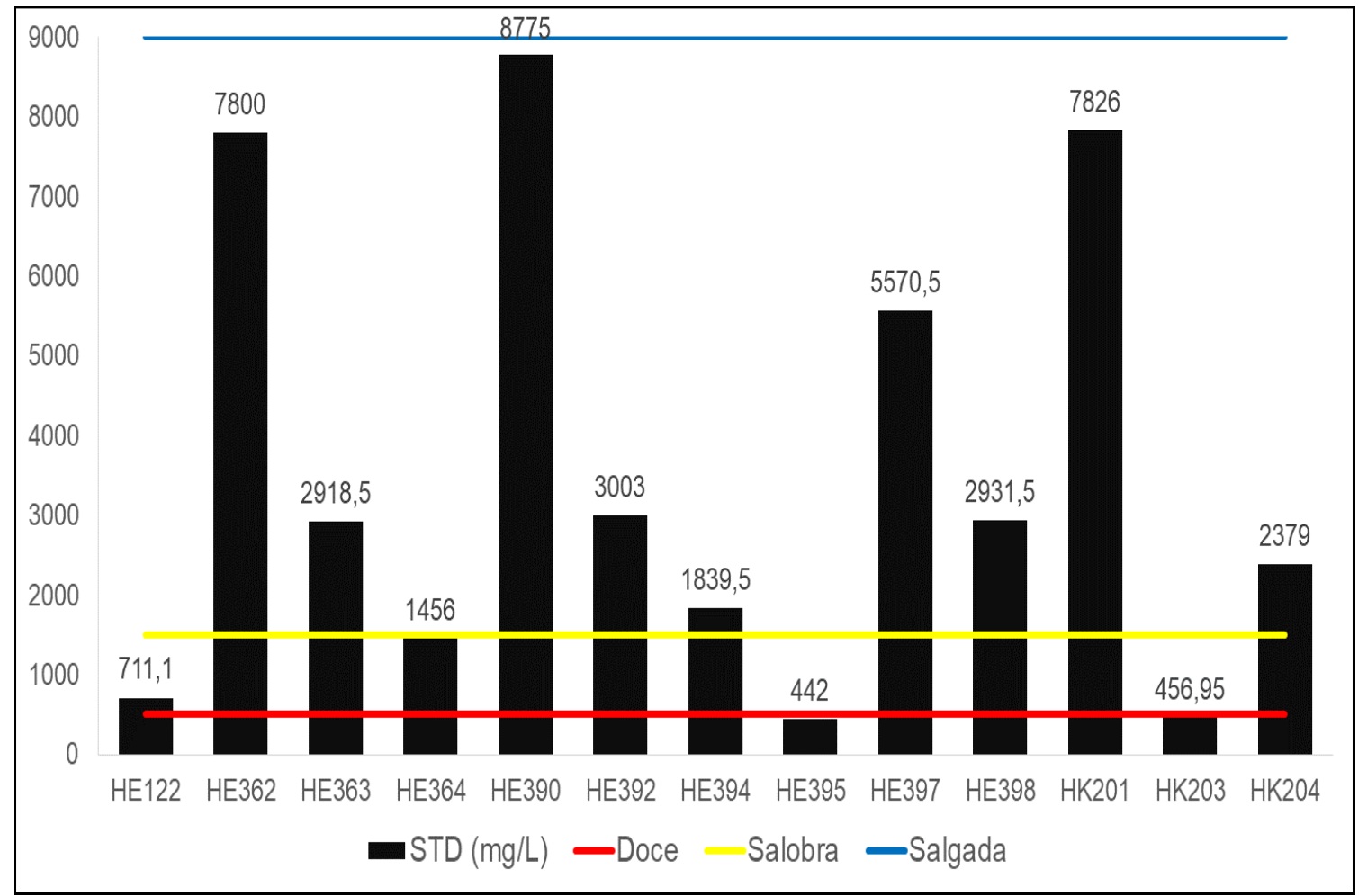

Fonte: Gráfico produzido a partir da base de dados de Mascarenhas et al. (2005).

Observando a elevação do relevo adjacente, é possível inferir o caso de convergência de sais para essa área depressiva ao longo do Holoceno, através de drenagens efêmeras, que associado a elevada evapotranspiração, promove ascensão capilar dos sais do lençol freático para superfície (RIBEIRO et al., 2016), que podem ser abastecidos por percolação de águas de origem marinha (Figura 5).

Outro fato que reforça a hipótese desse ambiente ser historicamente vulnerável a hipersalinização, diz respeito ao componente vegetal encontrado nas margens desse sistema lacustre, visto pela grande presença de um substrato vegetal de formações halófitas, com amplas extensões desprovidas de vegetação vascularizada (Figura 6). 
Figura 5 - Relação de altitude, drenagem superficial e subsuperficial (percolação de águas marinhas) e Sólidos Totais Dissolvidos (mg/L) para constituir sistema lacustre vulnerável a hipersalização.

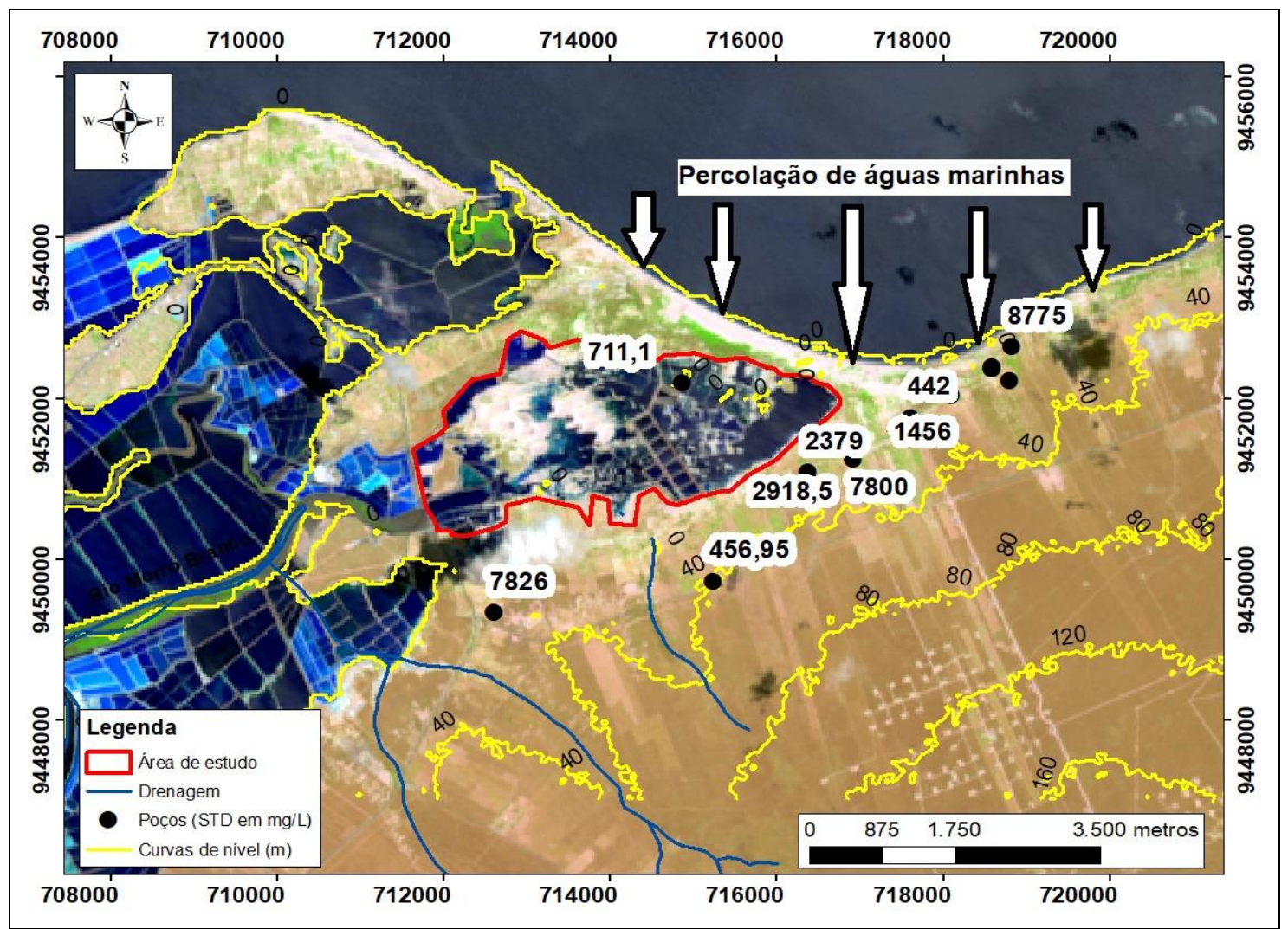

Fonte: Valores de STD obtidos da base de dados de Mascarenhas et al. (2005).

Figura 6 - Típicos vegetais halofítos presentes ao longo da área de estudo.

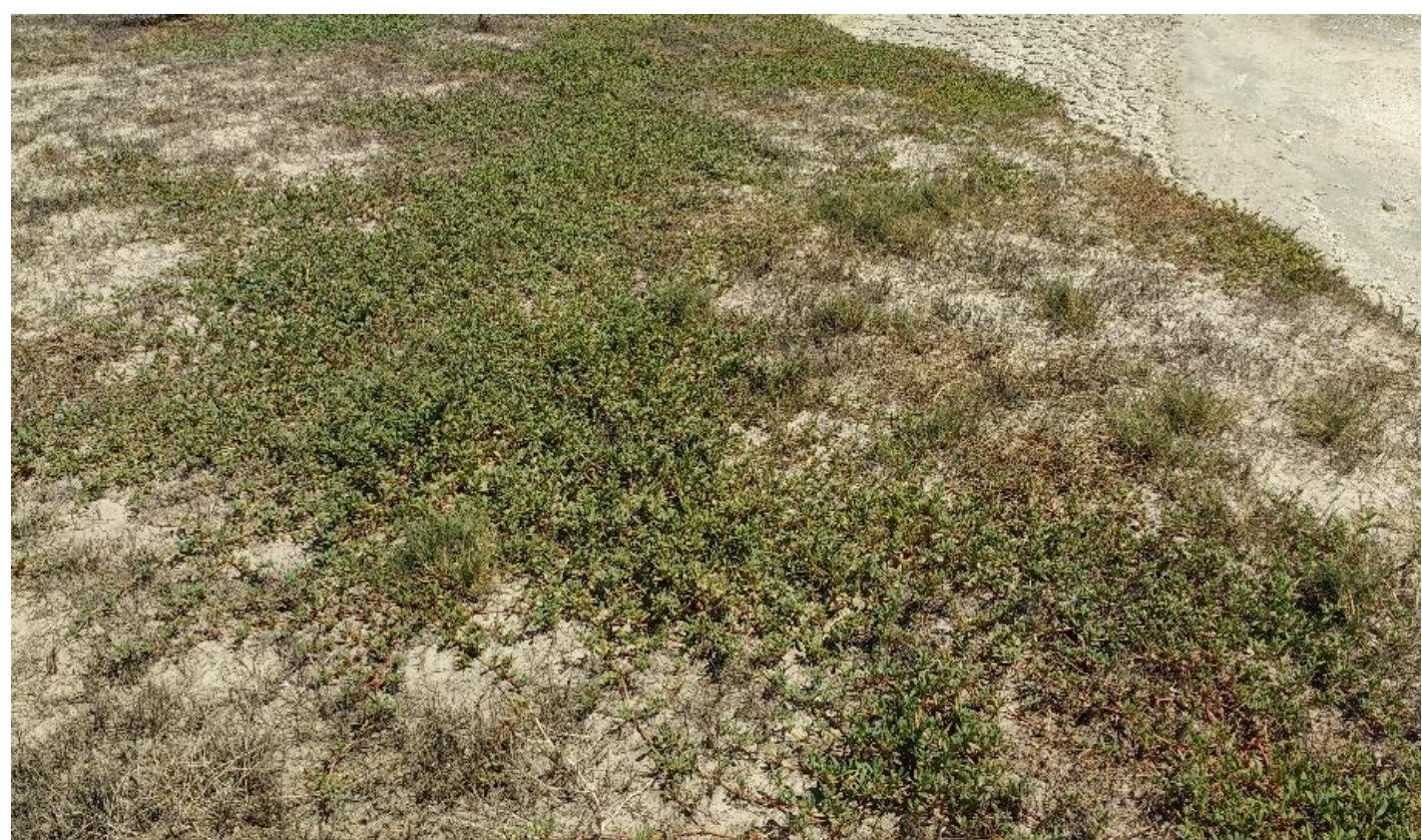

Fonte: Os autores (2018). 


\section{CONSIDERAÇÕES FINAIS}

Com base nos primeiros relatos de ocupação da área, sobretudo pelas intervenções realizadas (aterramento e obstrução de canal estuarino), que associadas ao contexto ambiental, sugerem condições geomorfológicas evolutivas ao longo do Quaternário, sendo caracterizado desde um sistema fluviomarinho para um sistema lacustre. No entanto, esse ambiente tornouse vulnerável a hipersalinização, como resultado das condições restritas de drenagem, lençol freático e a elevada evapotranspiração, que promove ascensão capilar dos sais para superfície.

Dessa forma, o elevado teor de sais no lençol influencia diretamente na ocorrência de hipersalinização temporária ou perene desse sistema lacustre. Infere-se a possibilidade dessas águas salinas emergirem a superfície, tornando-se um dos fatores ambientais preponderantes para a constituição de ambientes hipersalinos no litoral setentrional do Rio Grande do Norte, classificando essa lagoa como ambiente suscetível a hipersalinidade, e elevando-se para condições de deposição evaporítica.

\section{AGRADECIMENTOS}

Ao Programa de Pós-Graduação em Ciências Marinhas Tropicais - PPGCMT/UFC e a Coordenação de Aperfeiçoamento de Pessoal de Nível Superior - CAPES, pela concessão da bolsa de doutorado para o primeiro autor. Ao CNPq e Projeto Edital Universal- 431456/20160). À empresa Comércio e Indústria de Moagem e Refinação Santa Cecília Ltda - CIMSAL pelo apoio logístico nas atividades de campo e disponibilização de acervo bibliográfico.

\section{REFERÊNCIAS}

ARRULANATHAN, K., WIYERATNE, M. S.,RYDBERG, L. CEDERLOEF, U. Water exchange in a hypersaline tropical estuary, the Puttalam Lagoon, Sri Lanka. Ambio, v.24, p. 438-443, 1995.

BEZERRA, F.H.R.; BARRETO, A.M.F.; SUGUIU, K. Holocene sea-level history on the Rio Grande do Norte State coast, Brazil. Marine Geology, 2003.

BAYLY, I. A. E. The general biological classification of aquatic environments with special reference to those of Australia. En: WEATHERLEY, A. H. (ed.) Australia island water and their fauna: eleven studies. Nat. Univ. Press. Camberra, 1967.

BURLING, M. C., IVEY, G. N., PATTIARATCHI, C. B. Convectively driven exchange in a shallow coastal embayment. Continental Shelf Research, 19, 1599-1616, 1999.

CRUZ, W. B; MELO, F.A.F. Estudo geoquímico preliminar das águas subterrâneas do 
Nordeste do Brasil. Recife: SUDENE,1968.

GUTTIEREZ DE VELASCO, G. WINANT, C. D- and density-driven circulation in a wellmixed inverse estuary. Journal of Physical Oceanography, 34, p.1103-1116, 2004.

KJERFVE, B. Coastal Lagoons Processes. In: KJERFVE, B. (Ed.). Coastal Lagoons Processes, Berlin: Elsevier Oceanography Series, 1994.

KJERFVE, B.; SCHETTINI, C.A.F.; KNOPPERS, B.; LESSA, G.; FERREIRA, H.O. Hydrology and salt balance in a large, hypersaline coastal lagoon: Lagoa de Araruama, Brazil. Estuarine, Coastal and Shelf Science, v. 42, p. 701-725, 1996.

MAIA, R.P.; BEZERRA, F.H.R. Geomorfologia e neotectônica da bacia hidrográfica do Rio Apodi-Mossoró - NE/Brasil. Mercator, p. 209-228, 2012.

MARTIN, L.; DOMINGUEZ, J. M. L. Geological history of coastal lagoons. In: KJERVE, B. Coastal Lagoon Processes. London: Elsevier Oceanography Series, p. 41-66, 1994.

MASCARENHAS, J. C. (et. al.) (orgs.). Projeto cadastro de fontes de abastecimento por água subterrânea: Diagnóstico do município de Areia Branca/RN. Recife: CPRM/PRODEEM, 2005. 20 p.

MEDEIROS, D.H.M. Ambientes hipersalinos no litoral semiárido brasileiro: zona estuarina do Rio Apodi - Mossoró (RN). Dissertação (Mestrado em Geografia) - Programa de Pós Graduação em Geografia. Universidade Estadual do Ceará, Fortaleza, 2016.

MEDEIROS, D.H.M.; CAVALCANTE, A.A.; PINHEIRO, L.S. Respostas dos padrões de sedimentação e hipersalinidade na cobertura vegetal de planície estuarina sob influência da semiaridez. Geosul, v. 33, n. 66, p. 70-84, 2018.

MIRANDA, L.B.; CASTRO, B.M.; KJERFVE, B. Princípios de oceanografia física de estuários. 2. ed. Editora da Universidade de São Paulo, São Paulo, 2012.

MORAIS, J.O.; IRION, G.F.; PINHEIRO, L.S.; MEDEIROS, C. Aspectos sedimentológicos comparativos entre o sistema estuarino do Malcozinhado e Lagoa da Encantada-Ceará. Essentia Revista de Cultura Ciência e Tecnologia, Sobral, v. 4, n. 1, p. 101-113, 2002.

MORAIS, J.O.; PINHEIRO, L.S. The effect of semi-aridity and damming on sedimentary dynamics in estuaries - Northeastern region of Brazil. Journal of Coastal Research, v. 64, p. 1540-1544, 2011.

NAHAS, E. L.,PATTIARATCHI, C. B., IVEY, G. N. Processes controlling the position of frontal systems in Shark Bay, Western Australia. Estuarine Coastal and Shelf Science, 65, p. 463-474, 2005.

OLIVEIRA, S.P. B.; BATISTA, J.J. Influência do Índice de Aridez e da Litologia nos 
Processos de Salinização das Águas do Aqüífero Fissural na Região Fissural na Região Semi-árida do Nordeste. ABRH-Vitória, 2008.

PINHEIRO, L.S. Riscos e Impactos Ambientais no Estuário do Rio Malcozinhado,

Cascavel-CE. Tese (Doutorado em Oceanografia) - Universidade Federal de Pernambuco, Recife, 2003.

PINHEIRO, L.S.; MORAIS, J.O. Interferências de barramentos no regime hidrológico do Estuário do Rio Catú - Ceará - Nordeste do Brasil. Sociedade \& Natureza, Uberlândia, v. 22, n. 2, p. 237-250, 2010.

POSTMA, H. Water circulation and suspended matter in Baja California lagoons. Netherlands Journal of Sea Research 2, p. 566-604, 1965.

RAMOS SILVA, C.A. (Org.). Caracterização física, físico-química e química dos estuários Apodi, Conchas, Cavalos, Açu, Guamaré, Galinhos, Ceará-Mirim, Potengi, Papeba e Guaraíra. Instituto de Desenvolvimento Econômico e Meio Ambiente do Rio Grande do Norte/IDEMA, Natal, 2004.

RIBEIRO, M.R.; RIBEIRO FILHO, M.R.; JACOMINE, P.K.T. Origem e classificação dos solos afetados por sais. In: GUEYI, H.R.; DIAS, N.S.; LACERDA, C.F.; GOMES FILHO, E. (Orgs.). Manejo da salinidade na agricultura: estudos básicos aplicados. 2 ed. Fortaleza: INCTSal, 2016.

ROSADO, V.; ROSADO, A. Os holandeses nas salinas do rio Mossoró. Coleção Mossoroense, v. 333, 1987.

SCHOFF, S.L. Flushing of ancient sea water from Pre-Cambrian rocks in the upper Paraiba basin, State of Paraiba. SUDENE, Recife, 27p. 1967.

SMITH, S. V., ATKINSON, M. J. Mass balance of carbon and phosphorus in Shark Bay, Western Australia. Limnology and Oceanography, 28(4), p. 625-639, 1983.

SMITH, N. P. The Laguna Madre of Texas: hydrography of a hypersaline lagoon. In Hydrodynamics of Estuaries, Volume II, Estuarine Case Studies (Kjerve, B., ed.). CRC Press, Boca Raton, p. 21-40, 1988.

VALLE-LEVINSON, A.; SCHETTINI, C.A. Fortnightly switching of residual flow drivers in a tropical semiarid estuary. Estuarine, Coastal and Shelf Science, v. 169, p. 46 - 55, 2016.

WINANT, C. D., GUITTERIEZ DE VELASCO, G. Tidal dynamics and residual circulation in a well-mixed inverse estuary. Journal of Physical Oceanography, 33, 1365-1379, 2003. 